\title{
Profil Literasi Sains dalam Pembelajaran IPA di Era Covid-19: Studi Kasus di Universitas Terbuka
}

\author{
Mery Berlian $^{1 *}$, Iqbal Miftakhul Mujtahid ${ }^{2}$, Rian Vebrianto ${ }^{3}$, Musa Thahir ${ }^{4}$ \\ ${ }^{1}$ Program Studi Agribisnis, Universitas Terbuka \\ ${ }^{2}$ Program Studi Ilmu Administrasi Negara, Universitas Terbuka \\ ${ }^{3}$ Program Studi Magister PGMI, Universitas Islam Negeri Sultan Syarif Kasim Riau \\ ${ }^{4}$ Program Studi Pendidikan Matematika, Universitas Islam Negeri Sultan Syarif Kasim Riau \\ *Correspondence Address: mery@ecampus.ut.ac.id
}

\begin{abstract}
Literacy skills are fundamental things that students must have in facing the industrial era 4.0 to be able to meet the needs of life in various situations. Scientific literacy is the ability to understand science, communicate science, and apply science skills to solve problems. However, the scores of Indonesian students on scientific literacy abilities are still far below the international standard scores set by the OECD institution. Seeing this phenomenon, this study aims to describe the profile of students' scientific literacy abilities. The research method used was a survey method. Informants who were used as research samples were 1210 Open University students. Data on students' scientific literacy abilities were collected through an online questionnaire using Google Form, then analyzed descriptively using the help of the SPSS program version 23.00 for Windows. The findings obtained in this study indicate the importance of scientific literacy skills that have a positive impact on knowledge, understanding and skills in using media, especially social media, which is currently often used as a source of information by audiences, especially students. Seeing the results of this study, the researcher recommended the need for universities or leaders so that students could improve students' scientific literacy skills.
\end{abstract}

Keywords: ability, science literacy, natural science learning, covid-19 era, students.

\begin{abstract}
ABSTRAK
Kemampuan literasi merupakan hal fundamental yang harus dimiliki oleh mahasiswa dalam menghadapi era industri 4.0 untuk dapat memenuhi kebutuhan hidup dalam berbagai situasi. Literasi sains merupakan kemampuan untuk memahami sains, mengkomunikasikan sains, serta menerapkan kemampuan sains untuk memecahkan masalah. Namun, skor siswa Indonesia pada kemampuan literasi sains masih jauh di bawah skor standar internasional yang ditetapkan oleh lembaga OECD. Melihat fenomena tersebut, penelitian ini bertujuan untuk mendeskripsikan profil kemampuan literasi sains mahasiswa. Metode penelitian digunakan adalah metode survey. Informan yang dijadikan sampel penelitian sebanyak 1210 orang mahasiswa Universitas Terbuka. Data kemampuan literasi sains mahasiswa dikumpulkan melalui kuisioner online menggunakan Google Form, kemudian dianalisis secara deskritif menggunakan bantuan Program SPSS versi 23.00 for Windows. Temuan yang diperoleh pada penelitian ini menunjukan pentingnya kemampuan literasi sains yang memberikan dampak positif bagi pengetahuan, pemahaman dan keterampilan dalam menggunakan media terutama media sosial yang saat ini sering dijadikan sumber informasi oleh khalayak terutama oleh kalangan mahasiswa. Melihat hasil penelitian tersebut, peneliti merekomendasikan perlunya universitas atau pimpinan agar mahasiswa dapat meningkatkan kemampuan literasi sains mahasiswa.
\end{abstract}

Kata kunci: kemampuan, literasi sains, pembelajaran ipa, era covid-19, mahasiswa. 


\section{PENDAHULUAN}

Revolusi industri 4.0 merupakan salah satu dampak perkembangan informasi dan teknologi yang melaju dengan cepat hingga merambah ke semua sektor kehidupan, satu diantaranya adalah sektor pendidikan (Warsito et al., 2016). Era revolusi industri 4.0 ini juga dikenal dengan istilah revolusi digital. Hal ini dikarenakan semua informasi dapat diperoleh tanpa mengenal ruang dan waktu (Setyaningsih et al., 2019); dapat diakses internet kapan dan dimana saja (Cahyadi, 2019). Selain berdampak kepada sector pendidikam, industri 4.0 juga berdampak kepada kemampuan abad ke-21, yaitu TIK dan literasi digital sebagai tools for working (Griffin \& Care, 2015). Dengan demikian, dapat dipahami bahwa perkembangan TIK merupakan bagian dari munculnya era revolusi digital yang mampu memberikan pengaruh besar dan menguasai seluruh sektor kehidupan masyarakat, khususnya di dunia pendidikan. Salah satu literasi digital yang berdampak dalam proses pembelajaran adalah literasi sains.

Literasi sains pertama kali diperkenalkan oleh Paul DeHard Hurd pada tahun 1958 dalam artikel yang berjudul "Science literacy: Its meaning for American Schools", dan istilah tersebut telah digunakan untuk menggambarkan pemahaman tentang sains dan aplikasinya di masyarakat (Hurd, 1958; Laugksch, 2000; Holbrook \& Rannikmae, 2009). Literasi sains didefinisikan sebagai kemampuan menggunakan pengetahuan sains untuk mengidentifikasi pertanyaan, memperoleh pengetahuan baru, menjelaskan fenomena ilmiah dan menyimpulkan berdasarkan bukti-bukti ilmiah (Rahmania et al., 2015; Rubini et al., 2016; Vieira \& Tenreiro-Vieira, 2016; Bybee et al., 2009). Kemampuan tersebut dibutuhkan dalam rangka memahami serta membuat keputusan mengenai alam dan perubahan yang dilakukan terhadap alam melalui aktivas manusia (Katerina Ananiadou, 2009). Secara sederhana literasi sains diartikan sebagai kemampuan untuk memahami sains dan aplikasinya (Norris \& Phillips, 2003; Ristanto et al., 2017). Literasi sains sangat penting dimiliki oleh setiap mahasiswa. Mahasiswa yang memiliki kemampuan literasi sains akan dapat menerapkan pengetahuan mereka untuk memecahkan permasalahan dalam situasi kehidupan sehari-hari baik dalam lingkup pribadi, sosial atau pun global (OCDE, 2009). Holton menyebutkan bahwa literasi sains merupakan tujuan akhir dari pendidikan sains (Bybee et al., 2009).

Berdasarkan beberapa definisi literasi sains di atas, maka dapat disimpulkan bahwa literasi sains merupakan kemampuan seseorang untuk menggunakan pengertahuan ilmiahnya dalam menyelesaikan berbagai permasalahan sehari-hari berdasarkan bukti dan fakta yang telah diperoleh.

National Science Education Standards (NSES) (1996) menyatakan bahwa seseorang yang memiliki literasi sains akan memiliki pemahaman terhadap enam unsur utama dari literasi sains, yaitu: (1) sains sebagai inkuri; (2) konten sains; (3) sains dan teknologi; (4) sains dalam perspektif pribadi dan social; (5) sejarah dan sifat sains; dan (6) kesatuan konsep dan proses(National Research Council, 1996; Narut \& Supradi, 2019). Lebih lanjut, karakteristik seseorang yang memiliki literasi sains, yaitu seseorang yang memiliki kemampuan untuk menggunakan pengetahuan sains, untuk mengidentifikasi pertanyaan dan menarik kesimpulan berdasarkan bukti dalam rangka untuk memahami dan membantu membuat keputusan tentang lingkungan alam dan perubahan yang diakibatkan dari kegiatan manusia (OECD, 2013). Dengan literasi sains, maka seseorang memiliki kemampuan untuk terlibat dengan isu-isu terkait sains, dan dengan gagasan-gagasan sains sebagai cerminan masyarakat (OECD, 2013). Berdasarkan karakteristik tersebut, maka literasi sains tidak hanya dibutuhkan oleh orang yang ingin menjadi ilmuwan di masa depannya, tetapi juga merupakan kemampuan yang sangat penting dikuasai oleh semua warga negara.

Namun, tingkat literasi sains siswa menjadi salah satu permasalahan pendidikan di Indonesia. Meskipun pentingnya literasi sains sudah diakui oleh semua pendidik, tidak berarti bahwa literasi sains siswa terlatihkan dengan baik. Hal ini didukung oleh data pencapaian literasi sains siswa Indonesia dalam asesmen literasi sains PISA (OECD, 2016; Pratiwi, 2019; Puspitoningrum, 2019), tingkat membaca/literasi Indonesia berada pada peringkat 62 dari 70 negara dengan rata-rata skor 397. Rata-rata skor tingkat membaca/literasi dari 70 negara sebesar 493. Hal ini berarti tingkat 
membaca/literasi di Indonesia masih rendah (Pratama et al., 2019). Hal ini diperkuat oleh penelitian yang mengatakan bahwa literasi digital pada aspek content evaluation masih tergolong rendah (A'yuni, 2015). Rata-rata siswa yang bersekolah masih menerapkan literasi tradisional atau literasi bahan cetak (Brown, 2013). Berdasarkan hasil analisis tersebut, didapatkan informasi bahwa sebagian besar siswa Indonesia masih memiliki pengetahuan ilmiah yang terbatas yang hanya dapat diterapkan pada beberapa situasi saja. Mereka baru mampu memberikan penjelasan ilmiah yang sudah jelas dan mengikuti bukti-bukti yang eksplisit.

Berdasarkan permasalahan tersebut, upaya penting yang harus dilakukan adalah menyiapkan kualifikasi dan kompetensi mahasiswa yang berkualitas. Salah satu kualifikasi dan kompetensi guru yang diperlukan oleh seorang mahasiswa adalah keterampilan literasi sains. Dimana Perkembangan pengetahuan menuntut seseorang untuk menguasai dalam membaca dan memahami dokumen kompleks yang berisi gambar dan informasi. Saat membaca, menulis, mendengar, dan berbicara, penting bagi mahasiswa untuk memberi makna dan mengungkapkan ide melalui berbagai jenis media sebelum disampaikan kepada siswa (NCREL, 2003).

Sebagian Perguruan Tinggi telah mempersiapkan untuk menghadapi era industri 4.0 tanpa terkecuali Universitas Terbuka. Diantara keunggulan yang dimiliki UT adalah perkuliahan yang fleksibel, tidak ada batasan usia bagi mahasiswa, serta perkuliahan bisa dilakukan secara online sehingga bagi mahasiswa yang bekerja tidak perlu resign dari pekerjaannya (Setijadi, 2004). Adanya sistem perkuliahan online menguntungkan bagi masyarakat, namun di sisi lain bagi dapat menimbulkan kesukaran yang serius jika tidak dilengkapi dengan program Tutorial. Untuk itu, Universita Terbuka melakukan evaluasi yang sistematis terhadap mata kuliah yang bisa dipelajari sendiri atau perlu dilakukan proses pembimbingan oleh para Tutor sehingga proses pengajaran dan pengajaran di Universitas Terbuka akan berjalan dengan baik dan efisien. Namun, sejauh ini, nampaknya belum ada evaluasi tentang sejauh mana para mahasiswa memanfaat fasilitas berupa modul dalam proses pengembangan wawasan dan keterampilan dalam menyukseskan penguasaan dalam sebuah mata kuliah yang diemban dan diambilnya. Untuk itu, penelitian ini sangat penting untuk mengetahui peran dari fasilitas-fasilitas yang telah diberikan oleh Universitas Terbuka, apakah sangat signifikan atau hanya sebagai salah satu pemenuhan syarat saja tanpa memberikan efek positif bagi pengetahuan dan keterampilan baik pada Tutor maupun mahasiswa Universitas terbuka.

Pemetaan kemampuan literasi sains bagi para mahasiswa dianggap penting untuk melihat gambaran profil mahasiswa dari aspek ini dan apakah proses pembelajarn online atau modul (band out) lebih disukai oleh mahasiswa dalam menyelesaikan mata kuliah yang diambilnya.

\section{METODOLOGI}

Penelitian ini merupakan penelitian survey untuk melakukan pemetaan literasi sains mahasiswa. Data dalam penelitian ini dikumpulkan melalui instrument berupa, kuisioner (Creswell, 2012). Hal ini dilakukan sebagai upaya evaluasi dan identifikasi keterampilan literasi sains mahasiswa. Instrumen yang digunakan adalah instrumen kuisioner dengan skala 7 sesuai dengan teori literasi sains dengan nilai Alpha Cronbach 0,859, yang dinyatakan reliable sehingga dapat digunakan untuk mengukur dan mengevaluasi literasi sains mahasiswa. Adapun indicator yang digunakan dalam penelitian antara lain: (1) memiliki pengetahuan dan pemahaman konsep dan proses ilmiah; (2) menganalisis jawaban dari rasa ingin tahu didasarkan atas pengalaman; (3) kemampuan mendeskripsikan, menjelaskan dan memprediksi fenomena alam; (4) membaca dan memahami artikel ilmiah; (5) mengidentifikasi isu-isu ilmiah; dan (6) mengevaluasi kualitas informasi ilmiah. Hasil penyebaran kuisioner online dianalisis secara deskriptif menggunakan bantuan Program SPSS versi 23.00 for Windows. Adapun tahapan pengolahan data yang dilakukan penelitian adalah mengelompokkan data dengan beberapa tahapan, yaitu: memeriksa data yang sudah terkumpul, meliputi kelengkapan isian, memberikan kode pada setiap data yang terkumpul 
di setiap instrumen penelitian untuk memudahkan dalam penganalisisan dan penafsiran data, memasukkan data yang sudah dikelompokkan ke dalam tabel - tabel agar mudah dipahami, mengolah statistik sederhana agar data mempunyai arti dan dilakukan dengan beberapa macam teknik, seperti distribusi frekuensi (sebaran frekuensi) dan ukuran memusat (mean, median, modus).

\section{TEMUAN DAN PEMBAHASAN}

\section{Profil Subjek Penelitian}

Penelitian ini melibatkan 1210 mahasiswa PENDAS di Universitas Terbuka UPBJJ Pekanbaru. Data dianalisis secara deskriptif untuk menghasilkan profil subjek penelitian, yang ditunjukkan pada Tabel 1.

Tabel 1. Profil Subjek Penelitian

\begin{tabular}{|c|c|c|c|}
\hline Profil Penelitian & Kategori & $\mathbf{N}$ & Persentase (\%) \\
\hline \multirow[t]{2}{*}{ Jenis Kelamin } & Laki-laki & 408 & 34 \\
\hline & Perempuan & 802 & 66 \\
\hline \multirow[t]{3}{*}{ Lokasi Tempat Tinggal } & Kota & 169 & 14.0 \\
\hline & Kabupaten & 171 & 14.1 \\
\hline & Kecamatan & 870 & 71.9 \\
\hline \multirow[t]{2}{*}{ Memiliki Instansi/Tempat Kerja } & Ada & 1056 & 87.3 \\
\hline & Tidak Ada & 154 & 12.7 \\
\hline \multirow[t]{5}{*}{ Suku } & Melayu & 363 & 30.0 \\
\hline & Minang & 89 & 7.4 \\
\hline & Jawa & 557 & 46.0 \\
\hline & Batak & 116 & 9.6 \\
\hline & Lainnya & 85 & 7.0 \\
\hline \multirow[t]{4}{*}{ Umur } & $<20$ Tahun & 25 & 2.1 \\
\hline & 20 s.d. 25 Tahun & 350 & 28.9 \\
\hline & 25 s.d. 30 Tahun & 281 & 23.2 \\
\hline & $>30$ Tahun & 554 & 45.8 \\
\hline \multirow[t]{4}{*}{ Lama Kuliah di UT } & $<1$ Tahun & 232 & 19.2 \\
\hline & 1 s.d. 2 Tahun & 394 & 32.6 \\
\hline & 2 s.d. 3 Tahun & 183 & 15.1 \\
\hline & $>3$ Tahun & 401 & 33.1 \\
\hline \multirow[t]{4}{*}{ Biaya Kuliah } & Orang tua & 199 & 16.4 \\
\hline & Sendiri & 949 & 78.4 \\
\hline & Beasiswa & 13 & 1.1 \\
\hline & Pinjaman & 49 & 4.0 \\
\hline \multirow[t]{3}{*}{ Pekerjaan Orang Tua } & PNS & 173 & 14.3 \\
\hline & Wiraswasta & 916 & 75.7 \\
\hline & Honorer & 121 & 10.0 \\
\hline
\end{tabular}

Berdasarkan Tabel 1 diperoleh informasi bahwa mahasiswa Universitas Terbuka adalah 408 laki-laki (34\%) dan 802 perempuan (66\%). Walaupun perempuan lebih mendominasi daripada laki-laki yang dipilih sebagai subjek penelitian, namun perbedaan tersebut dianggap tidak terlalu signifikan. Dari data di atas juga diperoleh infromasi bahwa sebagian besar mahasiswa berasal dari daerah atau kecamatan sebanyak 870 orang $(71,9 \%)$. Selain itu, rata-rata mahasiswa memiliki instansi kerja sebanyak 1056 orang (87,3\%). Sementara itu, suku yang dianut oleh sebagian besar mahasiswa adalah suku Melayu dan Jawa masing-masing sebanyak 557 orang (46\%) dan 363 orang (30\%). Mahasiswa yang kuliah di Universitas Terbuka rata-rata berusia $>40$ tahun sebanyak 554 orang $(45,8 \%)$. Dengan usia mahasiswa yang dianggap senior, ternyata para mahasiwa sudah mengikuti perkuliahan yang cukup lama di Universitas Terbuka dengan rata lama 
kuliah $>3$ Tahun dan $1 \mathrm{~s} / \mathrm{d} 2$ Tahun masning-masing sebanyak 401 orang $(33,1 \%)$ dan 394 orang (32,6\%). Selain itu, para mahasiswa PENDAS Universitas Terbuka mengikuti melanjutkan perkuliahan dengan menggunakan biaya sendiri sebanyak 949 orang $(78,4 \%)$. Selanjutnya, sebagian besar pekerjaan orang tua mahasiswa paling banyak bekerja sebagai wiraswasta sebanyak 916 orang $(75,7 \%)$. Berdasarkan data profil penelitian di atas menunjukkan bahwa mahasiswa PENDAS Universitas Terbuka memiliki perbandingan gender yang ideal dan potensi untuk mengembangkan literasi digital.

Pada keterampilan saintifik pada mahasiswa kita peroleh nilai rata-rata sebesar 5,98 dengan kategori baik. Untuk lebih jelasnya, dapat dilihat pada Tabel 2 berikut.

Tabel 2. Profil Literasi Sains Mahasiswa

\begin{tabular}{|c|c|c|c|c|c|c|c|}
\hline \multirow{2}{*}{ Indikator Literasi Sains } & \multicolumn{2}{|c|}{$\mathbf{N}$} & \multirow{2}{*}{ Mean } & \multirow{2}{*}{$\begin{array}{l}\text { Std. } \\
\text { Dev. }\end{array}$} & \multirow{2}{*}{ Min. } & \multirow{2}{*}{ Max. } & \multirow{2}{*}{ Sum } \\
\hline & $\mathbf{V}$ & $\mathbf{M}$ & & & & & \\
\hline $\begin{array}{l}\text { Memiliki pengetahuan dan pemahaman konsep } \\
\text { dan proses ilmiah }\end{array}$ & 1210 & 0 & 4.79 & 1.27 & 1 & 7 & 5800 \\
\hline $\begin{array}{l}\text { Menganalisis jawaban dari rasa ingin tahu } \\
\text { didasarkan atas pengalaman }\end{array}$ & 1210 & 0 & 5.27 & 1.18 & 1 & 7 & 6373 \\
\hline $\begin{array}{l}\text { Kemampuan mendeskripsikan, menjelaskan dan } \\
\text { memprediksi fenomena alam }\end{array}$ & 1210 & 0 & 5.12 & 1.22 & 1 & 7 & 6200 \\
\hline Membaca dan memahami artikel ilmiah & 1210 & 0 & 5.06 & 1.22 & 1 & 7 & 6125 \\
\hline Mengidentifikasi isu-isu ilmiah & 1210 & 0 & 4.86 & 1.26 & 1 & 7 & 5879 \\
\hline Mengevaluasi kualitas informasi ilmiah & 1210 & 0 & 4.82 & 1.25 & 1 & 7 & 5838 \\
\hline Total & 7260 & 0 & 29.92 & 7.4 & 6 & 42 & 36215 \\
\hline Rata-rata & 1210 & $\mathbf{0}$ & 5.984 & 1.48 & 1.2 & 8.4 & 7243 \\
\hline
\end{tabular}

Berdasarkan Tabel 2, dapat diketahui bahwa profil penguasaan elemen literasi sains mahasiswa Universitas Terbuka memiliki rata-rata 5,98 atau 6 dengan kategori Baik. Perolehan kategori baik tersebut, dilihat dari tanggapan responden yakni mahasiswa yang telah mampu mengembangkan literasi sains dengan baik. Item pernyataan mahasiswa memiliki pengetahuan dan pemahaman konsep dan proses ilmiah memiliki rata-rata 4,79 dengan kategori baik. Item pernyataan mahasiswa menganalisis jawaban dari rasa ingin tahu didasarkan atas pengalaman memiliki rata-rata 5,27 dengan kategori baik. Item pernyataan mahasiswa memiliki kemampuan mendeskripsikan, menjelaskan dan memprediksi fenomena alam memiliki rata-rata 5,12 dengan kategori baik. Item pernyataan mahasiswa memiliki kemampuan membaca dan memahami artikel ilmiah memiliki rata-rata 5,06 dengan kategori baik. Item pernyataan mahasiswa memiliki kemampuan mengidentifikasi isu-isu ilmiah memiliki rata-rata 4,86 dengan kategori baik. Item pernyataan mahasiswa memiliki kemampuan mengevaluasi kualitas informasi ilmiah memiliki ratarata 4,82 dengan kategori baik. Dari hasil analisis deskriptif dapat diketahui bahwa, hasil dari tingkatan skor kemampuan scientific termasuk dalam kategori tinggi dengan mean 5,98 mempunyai jumlah frekuensi 1210 mahasiswa. Kategori ini menunjukkan bahwa mahasiswa universitas terbuka memiliki kemampuan scientific yang tinggi, dimana ditunjukkan juga oleh hasil kategorinya dalam prosentase yang tinggi.

Pendidikan sains saat ini diarahkan untuk mempersiapkan mahasiswa agar sukses hidup di abad-21. Salah satu keterampilan yang diperlukan dalam abad-21 adalah literasi saintifik (Liu, 2009). Literasi saintifik telah menjadi topik yang banyak dipelajari dan dimuat dalam berbagai jurnal pendidikan sains (Cavas et al., 2012). Tuntutan penguasaan literasi saintifik bagi masyarakat di tingkat national and international muncul karena semua orang wajib berpartisipasi dalam pemecahan masalah dunia nyata melalui pemahaman tentang sains dan teknologi yang dilandasi oleh penguasaan matematika, fisika, kimia, biologi, dan lingkungan (Cardwell, 2005). Literasi saintifik merupakan keterampilan hidup abad-21. Literasi saintifik merupakan keterampilan untuk hidup di era dimana pengetahuan ilmiah menjadi landasan dalam kehidupan sehari-hari (Nejla Gultepe, 2015). Literasi saintifik memandang pentingnya keterampilan berpikir dan bertindak yang 
melibatkan penguasaan berpikir dan menggunakan cara berpikir saintifik dalam mengenal dan menyikapi isu-isu sosial. Literasi saintifik berkembang sejalan dengan pengembangan life skills (Nejla Gultepe, 2015), yaitu perlunya keterampilan bernalar dan berpikir ilmiah dalam konteks sosial dan menekankan bahwa literasi saintifik diperuntukan bagi semua orang, bukan hanya kepada mereka yang memilih berkarir dalam bidang sains dan teknologi.

Konsep literasi sains mengharapkan siswa untuk memiliki rasa kepedulian yang tinggi terhadap diri dan lingkungannya dalam menghadapi permasalahan kehidupan sehari-hari dan mengambil keputusan berdasarkan pengetahuan sains yang telah dipahaminya (Wulandari, 2018). Literasi sains sebagai sebuah syarat yang harus dimiliki siswa dalam menyesuaikan tantangan perubahan zaman yang cepat sehingga dalam pembelajaran literasi dilatihkan secara beriringan dengan pengembangan life skill (Holbrook \& Rannikmae, 2009). Literasi sains penting untuk dikuasai oleh mahasiswa dalam kaitannya dengan bagaimana mahasiswa dapat memahami lingkungan hidup, kesehatan, ekonomi, dan masalah-masalah lain yang dihadapi oleh masyarakat modern yang sangat bergantung pada teknologi dan kemajuan serta perkembangan ilmu pengetahuan.

\section{SIMPULAN}

Berdasarkan analisis, hasil penelitian dan pembahasan yang sudah diungkapkan sebelumnya, diperoleh kesimpulan bahwa kemampuan literasi sains para mahasiswa Universitas Terbuka memiliki kategori baik (5,77). Selanjutnya, instrumen yang digunakan adalah kuisioner kemampuan literasi digital yang terdiri atas delapan konstruk dengan rata-rata nilai alpha croanbach sebesar 0,859 dengan kriteria tinggi. Perlu adanya penerapan pembelajaran dengan menggunakan pendekatan yang dapat mendukung untuk meningkatkan kemampuan literasi sains mahasiswa.

\section{PENGHARGAAN}

Kepada seluruh pihak-pihak yang mendukung dalam penelitian ini, peneliti sampaikan banyak terima kasih khususnya pihak Universitas Terbuka yang telah mendanai penelitian kompetitif ini pada tahun 2020 sehingga menghasilkan produk artikel.

\section{REFERENSI}

A'yuni, Q. Q. (2015). Literasi Digital Remaja di Kota Surabaya. Jurnal Fakultas Ilmu Sosial Dan Ilmu Politik Universitas Airlangga Surabaya, 4(2), 1-15. http://journal.unair.ac.id/literasi-digitalremaja-di-kota-surabaya-article-9195-media-136-category-8.html

Brown, C. (2013). Literacy Boost Indonesia Endline Report (Issue July).

Bybee, R., McCrae, B., \& Laurie, R. (2009). PISA 2006: An Assessment of Scientific Literacy. Journal of Research in Science Teaching, 46(8), 865-883. https://doi.org/10.1002/tea.20333

Cahyadi, I. F. (2019). Peranan Sistem Informasi Akuntansi dan Tantangan Profesi Akuntan di Era Revolusi Industri 4.0 (Sebuah Studi Fenomenologi). AKTS AR: Jurnal Akuntansi Syariah, 2(1), 69-82. https://doi.org/10.21043/aktsar.v2i1.5497

Cardwell, V. B. (2005). Literacy: What Level for Food, Land, Natural Resources, and Environment? Journal of Natural Resources and Life Sciences Education, 34(1), 112-117. https://doi.org/10.2134/jnrlse.2005.0112 
Cavas, B., Cavas, P., Ozdem, Y., Rannikmae, M., \& Ertepinar, H. (2012). Research Trends in Science Education from the Education from the Perspective of Journal of Baltic Science Education: A Content Analysis from 2002 to 2011. Journal of Baltic Science Education, 11(1), 94-103.

Creswell, J. W. (2012). Educational Research: Planning, Conducting Abd Evakuating Quantitative dan Qualitative Research (4th ed.). Pearson Education, Inc.

Griffin, P., \& Care, E. (2015). Assessment and Teaching of 21st Century Skills. In Springer Dordrecht Heidelberg. Springer. https://doi.org/10.1007/978-94-017-9395-7_15

Holbrook, J., \& Rannikmae, M. (2009). The Meaning of Scientific Literacy. International Journal of Environmental \& Science Education, 4(3), 275-288. https://doi.org/10.1097/00006199195402000-00010

Hurd, P. D. (1958). Science Literacy: Its Meaning for American Schools. Educational Leadership, 16(1), 13-16.

Katerina Ananiadou, M. C. (2009). 21st Century Skills and Competences for New Millennium Learners in OECD Countries. OECD Publishing.

Laugksch, R. C. (2000). Scientific literacy: A conceptual overview. Science Education, 84(1), 71-94. https://doi.org/10.1002/(SICI)1098-237X(200001)84:1<71::AID-SCE6>3.0.CO;2-C

Liu, X. (2009). Beyond science literacy: Science and the public. International Journal of Environmental and Science Education, 4(3), 301-311.

Narut, Y. F., \& Supradi, K. (2019). Literasi Sains Peserta Didik Dalam Pembelajaran IPA di Indonesia. Jurnal Inovasi Pendidikan Dasar, 3(1), 61-69.

National Research Council. (1996). National Science Education Standards. National Academy Press.

NCREL, M. G. (2003). enGange 21st Century Skills: Digital Literacy for Digital Age. Carol I" National Defence University.

Nejla Gultepe, Z. K. (2015). Effect of Scientific Argumentation on the Development of Scientific Process Skills in the Context of Teaching Chemistry. International Journal of Environmental and Science Education, 10(1), 111-132. https://doi.org/10.12973/ijese.2015.234a

Norris, S. P., \& Phillips, L. M. (2003). How Literacy in Its Fundamental Sense Is Central to Scientific Literacy. Science Education, 87(2), 224-240. https://doi.org/10.1002/sce.10066

OCDE. (2009). PISA 2009 Assessment Framework. Key Competencies in Reading, Mathematics and Science. In Assessment (Vol. 20, Issue 8). https://doi.org/10.1787/9789264062658-en

OECD. (2013). PISA 2012 Assessment and Analytical Framework: Mathematics, Reading, Science, Problem Solving and Financial Literacy. OECD Publishing. https://doi.org/http://dx.doi.org/10.1787/97892641 90511-en

OECD. (2016). Country Note - Results from PISA 2015: Indonesia. In OECD. https://www.oecd.org/pisa/PISA-2015-Indonesia.pdf 
Pratama, W. A., Hartini, S., \& Misbah. (2019). Analisis Literasi Digital Siswa Melalui Penerapan E-Learning Berbasis Schology. Jurnal Inovasi Dan Pembelajaran Fisika, 6(1), 9-13.

Pratiwi, I. (2019). Efek Program Pisa terhadap Kurikulum di Indonesia. Jurnal Pendidikan Dan Kebudayaan, 4(1), 51-71. https://doi.org/10.24832/jpnk.v4i1.1157

Puspitoningrum, E. (2019). Implementasi Literasi Untuk Meningkatkan Motivasi Pembelajaran Pada Materi Membaca Aksara Jawa Siswa SMA. Journal of Chemical Information and Modeling, 53(9), 1689-1699. https://doi.org/10.1017/CBO9781107415324.004

Rahmania, S., Miarsyah, M., \& Sartono, N. (2015). Perbedaan Kemampuan Literasi Sains Siswa dengan Gaya Kognitif Field Independent dan Field Dependent. Biosfer, 8(2), 27-34. https://doi.org/ISSN 0853-2451

Ristanto, R. H., Zubaidah, S., Amin, M., \& Rohman, F. (2017). Scientific Literacy of Students Learned Through Guided Inquiry. International Journal of Research \& Review, 234(5), 23-30. https://www.ijrrjournal.com/IJRR_Vol.4_Issue.5_May2017/IJRR004.pdf

Rubini, B., Ardianto, D., Pursitasari, I. D., \& Permana, I. (2016). Identify Scientific Literacy from The Science Teachers' Perspective. Jurnal Pendidikan IPA Indonesia, 5(2), 299-303. https://doi.org/10.15294/jpii.v5i2.7689

Setijadi, E. . (2004). Universitas Terbuka, Dulu, Kini, dan Esok 20 Tabun. Universitas Terbuka.

Setyaningsih, R., Abdullah, Prihantoro, E., \& Hustinawaty. (2019). Model Penguatan Literasi Digital Melalui Pemanfaatan E-Learning. Jurnal ASPIKOM, 3(6), 1200-1214. https://doi.org/10.24329/aspikom.v3i6.333

Vieira, R. M., \& Tenreiro-Vieira, C. (2016). Fostering Scientific Literacy and Critical Thinking in Elementary Science Education. International Journal of Science and Mathematics Education, 14(4), 659-680. https://doi.org/10.1007/s10763-014-9605-2

Warsito, Bimatara, M., \& Djuniadi, D. (2016). Pengembangan E-Learning Berbasis Schoology pada Mata Pelajaran Matematika Kelas VII. Jurnal Pendidikan Matematika FKIP Unissula, 4(1), 91-99.

Wulandari, S. (2018). Analisis Kemampuan Literasi Sains Pada Aspek Pengetahuan dan Kompetensi Sains Siswa SMP Pada Materi Kalor. Edusains, 8(1), 66-73. 